\title{
Serotonin Promotes the Differentiation of Glutamate Neurons in Organotypic Slice Cultures of the Developing Cerebral Cortex
}

\author{
Alexandros A. Lavdas, ${ }^{1}$ Mary E. Blue, ${ }^{2}$ Jill Lincoln, ${ }^{1}$ and John G. Parnavelas ${ }^{1}$ \\ ${ }^{1}$ Department of Anatomy and Developmental Biology, University College London, London WC1E 6BT, United Kingdom, \\ and $2 K e n n e d y$ Krieger Research Institute and Department of Neurology, The Johns Hopkins University School of \\ Medicine, Baltimore, Maryland 21205
}

The monoamines serotonin (5-HT), noradrenaline (NA), and dopamine (DA), which are present in the developing brain apparently before they assume their neurotransmitter functions, are regarded as strong candidates for a role in the maturation of the cerebral cortex. Here we sought to investigate their effects on the generation and differentiation of cortical cell types. Slice cultures, prepared from the cortices of embryonic day (E) 14, $\mathrm{E} 16$, and E19 rat fetuses, were kept in defined medium or in defined medium plus 5-HT for $7 \mathrm{~d}$. E16 cortices were also exposed to NA or DA for the same period. At the end of this period, the proportions of the neuronal [glutamate (Glu)-, GABA-, calbindin-, calretinin-labeled], glial (GFAP), and neuroepithelial (nestin) cell types were estimated for all conditions. We found that in E16 cultures, application of 5-HT, but not of NA or DA, significantly increased the proportion of Glu-containing neurons without affecting the overall neuronal population or the proportions of any other cell types. A similar effect was observed in co-cultures of E16 cortex with slices through the midbrain raphe nuclei of E19 rats. The total amount of cortical Glu, as measured with HPLC, was also increased in these co-cultures. To investigate whether the effect of 5-HT was the result of changes in cell proliferation, we exposed slices to bromodeoxyuridine (BrdU) and found that the proportion of BrdU-labeled cells was similar in the 5-HT-treated and control slices. These results indicate that 5-HT promotes the differentiation of cortical Glu-containing neurons without affecting neuroepithelial cell proliferation.

Key words: neocortex; development; monoamines; 5-HT; neurons; glutamate; BrdU; slice cultures
All areas of the cortex contain two main types of neurons, the pyramidal and nonpyramidal cells, in approximately the same proportions (Rockel et al., 1980). These neurons show characteristic morphological (Szentágothai, 1973), neurochemical (Parnavelas et al., 1989), and functional (Gilbert, 1983; McCormick et al., 1985) properties. Pyramidal neurons, the projection cells of the cortex, use the excitatory neurotransmitters L-glutamate (Glu) or L-aspartate at their sites of projection in the cortex and in subcortical target areas (Fagg and Foster, 1983; Dori et al., 1992). The nonpyramidal cells are the cortical interneurons that exert an inhibitory effect on cells of the cortex by releasing GABA (Sillito, 1984). Astrocytes and oligodendrocytes are the main glial cell types in the cortex (Parnavelas et al., 1983).

All neurons in the cortex have their origin in the ventricular zone that lines the telencephalic ventricles during embryonic development. The mechanisms deployed for generating the cellular diversity from a seemingly homogeneous population of progenitor cells in the ventricular zone are not yet known, but several lines of evidence suggest that both inherited and local environmental factors are involved (for review, see McConnell, 1991).

Signals arising within the ventricular zone have been shown to

Received June 25, 1997; revised August 4, 1997; accepted August 5, 1997.

This work was supported by the Wellcome Trust (Grant 038015 to J.G.P.) and National Institutes of Health (Grant NS29167 to M.E.B.). We thank Christopher Kwon and Madhusudhan Annadata for technical assistance, and Drs. Marina Mione and Yiannis Pappas for advice and helpful suggestions. We are grateful to Drs. R. McKay and A. Frankfurter for the gifts of the nestin and TUJ1 antibodies.

Correspondence should be addressed to John G. Parnavelas, Department of Anatomy and Developmental Biology, University College London, Gower Street, London WC1E 6BT, UK

Copyright $\odot 1997$ Society for Neuroscience $0270-6474 / 97 / 177872-09 \$ 05.00 / 0$ regulate the proliferation and differentiation of neuroepithelial cells, thus having important roles in the generation of the cell diversity in the developing cortex. Such signals include neurotrophic factors (Temple and Qian, 1995), extracellular matrix molecules (Ferri and Levitt, 1995), and neurotransmitters (LoTurco et al., 1995). A number of neurotransmitters have been identified in the developing nervous system, including the cerebral cortex, before the formation of synapses, and evidence points to their involvement in developmental processes before their function in synaptic transmission (Parnavelas et al., 1988; Lauder, 1993; Levitt et al., 1997).

The neurotransmitters serotonin (5-HT), noradrenaline (NA), and dopamine (DA) are contained in axonal systems that originate in the brainstem and midbrain and provide an extensive innervation of the cortical mantle (for review, see Parnavelas et al., 1989). These monoaminergic systems are some of the earliest transmitter systems to appear in the rostral telencephalon, arriving at the early stages of neurogenesis, and the development of their patterns of innervation appears to coincide with neuronal proliferation and differentiation in the cortex (Levitt and Moore, 1979; Lidov and Molliver, 1982a; Wallace and Lauder, 1983; Berger and Verney, 1984; Kalsbeek et al., 1988). The early arrival of these fiber systems has prompted speculation that they may be involved in the maturation of the cortex, but studies have so far focused on their effects in synapse formation and plasticity and in the morphological maturation of cortical cells and their connections (Kasamatsu and Pettigrew, 1976; Chubakov et al., 1986; Lauder, 1990; Bennett-Clarke et al., 1994). Here we used organotypic slice cultures of rat cerebral cortex to test the hypothesis that monoamines influence the differentiation of cortical neurons. 
The results indicated that 5-HT, but not NA or DA, promoted the differentiation of Glu-containing neurons, whereas it had no effect on any of the other neuronal or glial cell types.

\section{MATERIALS AND METHODS}

Materials. 5-HT, NA, DA, and most culture media and supplements were purchased from Sigma (St. Louis, MO), with the exception of bovine holo-transferrin (Life Technologies, Gaithersburg, MD). Antibodies used in this study were rabbit anti-Glu (Sigma), rabbit anti-GABA (Sigma), rabbit anti-calbindin- $\mathrm{D}_{28 \mathrm{KD}}(\mathrm{CB}$; SWant, Switzerland), rabbit anti-calretinin (CR; SWant), rabbit anti-nestin (gift of Dr. R. McKay, National Institutes of Health), rabbit anti-fibrillary acidic protein (GFAP; Dakopatts, Copenhagen, Denmark), rabbit anti-5-HT (Incstar, Stillwater, MN), mouse anti-TUJ1 (gift of Dr. A. Frankfurter), mouse anti-bromodeoxyuridine (BrdU; Sigma), and biotinylated goat antirabbit and goat anti-mouse (Vector Laboratories, Burlingame, CA). Other materials used were avidin and biotin (Vector), fetal calf serum (FCS; Life Technologies), normal goat serum (NGS; Sera-Lab, Sussex, UK), Gays balanced salt solution (GBSS; Life Technologies), HBSS (ICN Biochemicals, Montréal, Québec, Canada), $30 \mathrm{~mm}$ culture plate inserts (Millipore, Bedford, MA), and penicillin/streptomycin (P/S; ICN). Diaminobenzidine (DAB) tablet sets, EDTA, agar, and low gelling temperature agarose were all purchased from Sigma. Materials used for HPLC were sodium phosphate dibasic (Microselect; Fluka, Buchs, Switzerland), sodium phosphate monobasic (Ultrapure; J.T. Baker, Phillipsburg, NJ), sodium tetraborate, $\beta$-mercaptoethanol (BME), methanol (Baxter, Deerfield, IL), perchloric acid (69\%), phosphoric acid $(85 \%)$, and opthalaldehyde (OPA) (Eastman Kodak). All amino acids were purchased from Sigma.

Preparation of slice cultures. Pregnant Sprague Dawley albino rats were killed by cervical dislocation at 14,16 , and $19 \mathrm{~d}$ of gestation (E14, $n=20$; $\mathrm{E} 16, n=50 ; \mathrm{E} 19, n=30$ ). The fetuses were rapidly removed and placed in GBSS at $4^{\circ} \mathrm{C}$ supplemented with glucose $(6.5 \mathrm{mg} / \mathrm{ml})$. The following procedures were all performed under sterile conditions. The brains were removed and placed in a $3 \%$ solution of agar in $0.1 \mathrm{M}$ PBS, $\mathrm{pH} 7.2$, at $40^{\circ} \mathrm{C}$. The agar was subsequently hardened on ice, and the brains were cut with a Vibroslice (Campden Instruments) at $400 \mu \mathrm{m}$. Slices were kept for $50 \mathrm{~min}$ in GBSS/glucose at $4^{\circ} \mathrm{C}$ to allow for deterioration of enzymatic activity released by damaged cells. In each experiment, the slices taken from the cerebral wall of all the embryos of a pregnant rat were dissected out and placed onto millicell $\mathrm{CM}$ membranes in $30 \mathrm{~mm}$ petri dishes containing $1 \mathrm{ml}$ of either defined medium (DM) or DM+monoamine, plus 5\% FCS for the first day in vitro (DIV), after which they were kept in the absence of serum. DM consisted of DMEM/F12 mixture supplemented with $6.5 \mathrm{mg} / \mathrm{ml}$ glucose, $0.1 \mathrm{~mm}$ glutamine, $100 \mathrm{mg} / \mathrm{ml} \mathrm{P} / \mathrm{S}, 100$ $\mu \mathrm{g} / \mathrm{ml}$ bovine serum albumin, $5 \mu \mathrm{g} / \mathrm{ml}$ insulin, $20 \mathrm{~nm}$ progesterone, 16 $\mu \mathrm{g} / \mathrm{ml}$ putrescine, $30 \mathrm{~nm}$ selenium, $0.4 \mathrm{ng} / \mathrm{ml}$ thyroxine, $100 \mathrm{mg} / \mathrm{ml}$ transferrin, and $0.3 \mathrm{ng} / \mathrm{ml}$ triiodothyronine. 5-HT $(200 \mu \mathrm{M})$, NA $(100$ $\mu \mathrm{M})$, or DA $(50 \mu \mathrm{M})$ was added to the medium of E16 slices for the duration of the culture period, normally 7 d; E14 and E19 cultures were exposed to 5-HT only. In seven experiments, co-cultures were prepared in which slices containing the raphe nuclei of E19 rat embryos (Altman and Bayer, 1995) were placed onto the membranes adjacent to E16 cortical slices; these cultures were grown in DM only. In all cultures, the medium was exchanged every second day.

Immunohistochemistry. At the end of the culture period, slice cultures from four experiments were fixed with $4 \%$ paraformaldehyde in 0.1 PBS and processed as whole mounts for Glu or GABA immunohistochemistry (10 slices each) to qualitatively assess their neurochemical composition. Slices taken from three experiments (control and 5-HT-treated cultures) were also fixed, sectioned with a cryostat at $15 \mu \mathrm{m}$, and stained with an antibody against TUJ1, a marker of immature neurons (1:500) (Lee et al., 1990). All other cultures were dissociated, embedded in agarose, and immunostained as described by Vaccarino et al. (1995). According to this method, the medium was washed away with $0.1 \mathrm{M}$ PBS, and slices were dissociated with $0.25 \%$ trypsin containing $0.003 \%$ EDTA. In the case of the co-cultures, the cortical slice was separated from the slice of midbrain, using a razor blade, and transferred into a different petri dish before dissociation. Thirty minutes later, the cell suspension was centrifuged at $200 \times g$ for $3 \mathrm{~min}$. The supernatant was then removed, and the cells were resuspended and fixed with $4 \%$ paraformaldehyde in PBS for $1 \mathrm{hr}$. They were subsequently washed in PBS and resuspended in a solution of $1.8 \%$ low gelling point agarose in $0.1 \mathrm{M}$ PBS at $45^{\circ} \mathrm{C}$. The agarose solution containing the cells was then poured between two glass slides separated by two No. 1 coverslips and was left to set in the refrigerator for $10 \mathrm{~min}$. Pieces of the agarose films containing the cells were subsequently incubated with one of the following cell-specific markers: anti-Glu (1:500), anti-GABA (1:500), anti-CB or anti-CR (1: 1000; subpopulations of nonpyramidal cells) (Baimbridge et al., 1992), anti-nestin (1:1000; neuroepithelial cells) (Lendahl et al., 1990), or antiGFAP (1:500; astrocytes). The bound immunoglobulins were visualized with the avidin-biotin-peroxidase (ABC) method using DAB as substrate. E16 cultures that were kept for 10 DIV were stained only for Glu and GABA. The stained agarose films were mounted on slides (in PBS-glycerol), and fields of labeled cells were observed under the microscope. The total number of cells and the number of immunostained cells per field were counted in randomly selected fields with the use of a $250-\mu \mathrm{m}$-square reticule under a $20 \times$ objective lens. A minimum of 10 fields ( $\sim 500$ cells) were counted in each of four separate experiments for each culture condition, and the proportion of immunostained cells in the whole cell population was calculated for each experiment. Student's $t$ test was used to compare the mean percentages of cells stained with each antibody in the control group with those in the cortices exposed to monoamines and in the co-cultures. To assess the state of differentiation of cortical neurons at the start of the culture, cortices of E14, E16, and E19 fetuses (three rats at each age) were acutely dissociated, embedded in agarose, immunostained, and analyzed as described above.

To examine whether the axons of 5-HT-containing neurons in the raphe nuclei innervated the cortical slices during the culture period, raphe-cortex co-cultures were fixed with $4 \%$ paraformaldehyde in PBS for $1 \mathrm{hr}$ and removed from the membranes en bloc. They were then stained as whole mounts with anti-5-HT antibody (1:500 in PBS containing $0.5 \%$ Triton $\mathrm{X}-100$ and $10 \%$ NGS overnight at room temperature) using the $\mathrm{ABC}$ method and $\mathrm{DAB}$ as substrate.

HPLC. HPLC was used to measure the levels of 5-HT in the culture medium of cortical slices and the amount of cortical Glu in the co-culture experiments. The concentration of 5-HT in the culture medium was measured at $6 \mathrm{hr}$ intervals over the $2 \mathrm{~d}$ period between the start of the culture and the first change of medium. For this procedure, nine cultures were prepared from three animals, and $200 \mu \mathrm{l}$ samples were removed from the culture medium at each time point. Three cultures were sampled at a time, so that the total volume of the medium available to the slices would not decrease significantly. These samples were diluted 1:10 with $0.1 \mathrm{M}$ perchloric acid with $0.4 \mathrm{~mm}$ sodium bisulfite. After low-speed centrifugation, the supernatants were used for measurements of 5-HT with HPLC as described by Reinhard et al. (1980). Separation was achieved with a C18 reverse-phase column (Spherisob ODS2, Hichrom Ltd., Reading, UK) using a mobile phase of $0.1 \mathrm{~m}$ sodium acetate buffer, $\mathrm{pH} 7.4$, containing $0.1 \mathrm{~mm}$ EDTA and $12 \%(\mathrm{v} / \mathrm{v})$ methanol at a flow rate of $2.0 \mathrm{ml} / \mathrm{min}$. Quantitation was achieved with a coulometric detector with the following settings: guard cell, $+0.35 \mathrm{~V}$; detector $1,+0.35 \mathrm{~V}$; detector $2,-0.30 \mathrm{~V}$.

For HPLC measurements of Glu, eight groups each of three control slices and nine groups of the same number of slices that had been co-cultured with raphe nuclei (taken from four pregnant rats) were frozen and stored at $-70^{\circ} \mathrm{C}$ until protein extraction. To extract protein, frozen cultures were gently removed from the membrane on which they had been grown, using ice-cold PBS, and their weights were determined. Ten volumes per weight of $0.2 \mathrm{~N}$ perchloric acid were added, and the tissue was sonicated on ice twice for $30 \mathrm{sec}$. The contents were then centrifuged at $8000 \times g$ for $1 \mathrm{~min}$. The supernatants were collected, filtered through Millipore filters, and frozen. These samples were stored at $-20^{\circ} \mathrm{C}$ until the amino acid analysis was performed. A modified HPLC method for isocratic separation and determination of amino acids was used to measure levels of Glu (Donzati and Yamamoto, 1988). The method used provided conditions that optimized the sensitivity, resolution, and stability of precolumn derivatization of amino acids using OPA and BME. Briefly, precolumn derivatization was performed by a Gilson 231 XL sampling injector with a $20 \mu \mathrm{l}$ titanium loop (autosampler). A diluted OPA/BME stock solution was mixed with the sample solution in a proportion of 2:1. To correct for injection variability, an internal standard (homoserine) was used in the sample preparation. After a $2 \mathrm{~min}$ incubation time, the samples were injected into an HR-80 reverse-phase column (ESA). Amino acids were detected with an ESA coulochem II multi-electrode detector, and the data were collected by a SP4400 integrator (Thermo Separation Products). Glu content, expressed as micromoles per liter, was determined by comparing the area under the peak for each amino acid versus a standard peak for that amino acid. Three measurements were taken from each culture group, and a mean was 


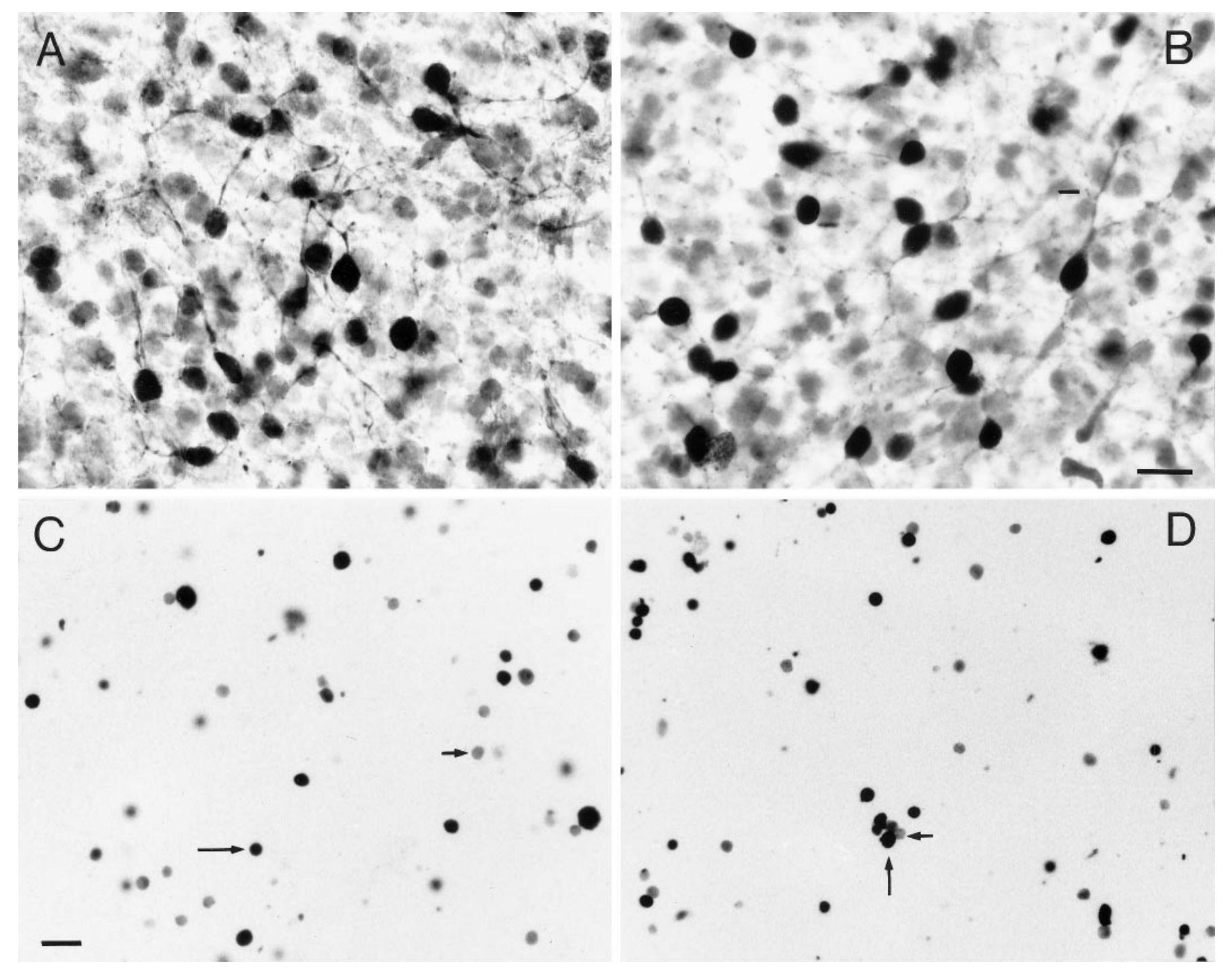

Figure 1. Immunolabeled cells from E16 cortices kept for 7 DIV, as they appeared in whole-mount preparations $(A, B)$ and after dissociation and embedding in agarose $(C, D)$. In the whole-mount preparations, Glu- $(A)$ and GABA-containing $(B)$ cells showed darkly stained somata with short and sparsely branched processes. In agarose films, cells labeled for Glu $(C)$ and GABA $(D)$ appeared round and darkly stained. Long arrows point to a number of labeled neurons, and short arrows point to some unlabeled cells. Scale bars: $A, B, 20 \mu \mathrm{m} ; C, D, 50 \mu \mathrm{m}$.

calculated. Eight such means from the controls and nine from the co-cultures were used in total, and the two conditions were compared using Student's $t$ test.

BrdU immunohistochemistry. In four experiments, slice cultures were exposed to $\mathrm{BrdU}\left(10^{-5} \mathrm{M}\right)$ for $16 \mathrm{hr}$ and then fixed with $4 \%$ paraformaldehyde in $0.1 \mathrm{M}$ PBS for $1 \mathrm{hr}$; different slices were exposed to BrdU at each of the 7 DIV. They were subsequently cryoprotected in $20 \%$ sucrose in PBS and sectioned at $10 \mu \mathrm{m}$ with a cryostat. The sections were collected onto poly-L-lysine-coated slides and treated with $2 \mathrm{~N} \mathrm{HCl}$ for 1 $\mathrm{hr}$. They were then incubated in $0.1 \mathrm{M}$ borate buffer, $\mathrm{pH} 8.4(2 \times 15 \mathrm{~min})$, rinsed with PBS, and stained with anti-BrdU (1:500 in PBS containing $0.25 \%$ Triton $\mathrm{X}-100$ and $5 \%$ NGS overnight at $4^{\circ} \mathrm{C}$ ) using the $\mathrm{ABC}$ method and $\mathrm{DAB}$ as substrate. The calculation of the mean percentage of labeled cells in the proliferative zones for each day and culture condition was performed as above.

\section{RESULTS}

\section{Slice cultures of developing cortex}

We first examined the state of differentiation of cortical neurons at the start of the culture by staining, using cell-specific markers, acutely dissociated cells from the cortices of E14, E16 and E19 rats. This experiment showed no Glu-labeled neurons at any of the three ages, in agreement with a recent study in tissue sections (Dori and Parnavelas, 1996), although elevated background staining was observed in cultures prepared from E19 animals; a very small number of GFAP-containing cells was seen in both the E16 and E19 cultures. No GABA staining was detected in E14 cultures, but at E16 and E19, GABA-containing neurons comprised $7.0 \pm 0.6$ and $8.8 \pm 0.7 \%$ of the cells, respectively. Both $\mathrm{CB}$ and $\mathrm{CR}$ neurons were detected as early as E14 comprising $5.4 \pm 0.3$ and $7.0 \pm 0.6 \%$ of all cells. At E19, when more cells appeared differentiated, these proportions declined to $3.2 \pm 0.4 \%$ for $\mathrm{CB}$ and $4.1 \pm 0.2 \%$ for CR. Nestin-labeled cells made up the vast majority of cells at E14 $(73.6 \%)$ and progressively smaller proportions at E16 (43.9\%) and E19 (26.7\%).

Whole-mount immunostained slices cultured for $7 \mathrm{~d}$ revealed the presence of both Glu- and GABA-containing neurons throughout the cortical thickness (Fig. $1 A, B$ ). The vast majority of these cells had intensely stained somata and a number of short and sparsely branched processes. In agarose films, cells labeled for cell-specific markers (Glu, GABA, CB, CR, nestin, GFAP) 

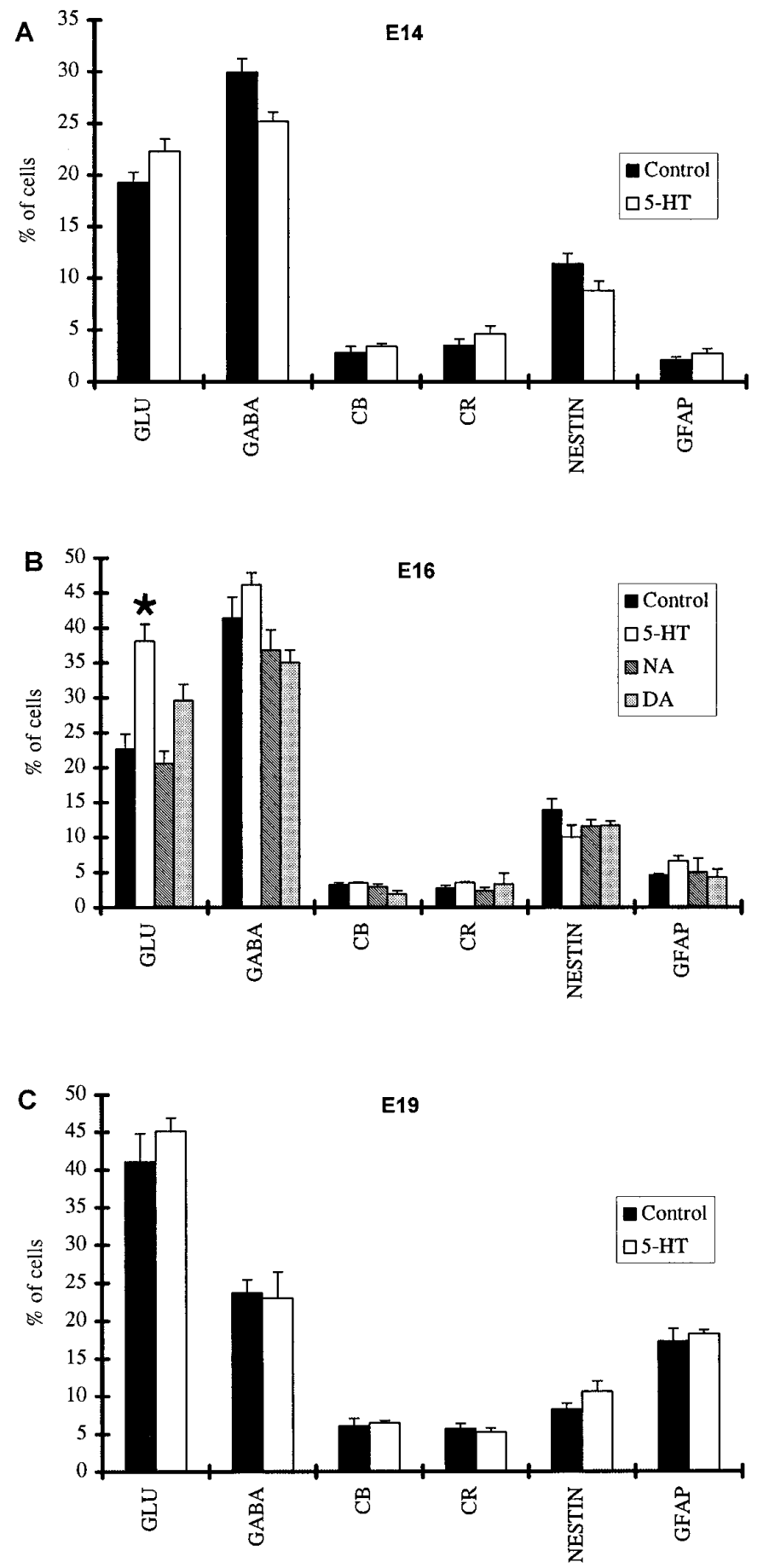

Figure 2. The proportions of cells immunoreactive for cell-specific markers (Glu, GABA, CB, CR, nestin, GFAP) in cortical slices prepared at E14 $(A)$, E16 $(B)$, and E19 $(C)$ and cultured both in the presence of a monoamine and under control conditions. The presence of 5-HT in the medium significantly increased the proportion of Glu-containing cells in cultures prepared at E16 ( $B$, asterisk indicates statistical significance).

appeared as round and darkly stained, often in clusters of three or more cells (Fig. 1C,D). Unlabeled cells showed light background staining, and their identification was confirmed at times with phase-contrast microscopy. Counts of labeled and unlabeled cells were made, and the proportion of each cell population was determined in control and monoamine-treated cultures (Fig. 2).
In slices prepared from E14 animals, the corresponding proportions of each cell type did not differ significantly in the control and 5-HT-treated cultures. Glu-labeled neurons were between 20 and $25 \%$ of the total cell population, GABA-containing neurons represented roughly $30 \%$, nestin-immunoreactive cells were $\sim 10 \%$, and CB-, CR-, and GFAP-labeled cells each comprised $<5 \%$ of the overall cell population (Fig. $2 A$ ).

In cultures prepared from E16 rats, the proportion of Glupositive cells was found to be significantly $(p=0.001)$ higher in the 5 -HT group $(38.1 \%)$ as compared with the control slice cultures $(22.8 \%)$, whereas no significant differences were found for the other cell types (Fig. $2 B$ ). The proportion of Glu-positive cells in E16 slices exposed to 5-HT only during the first $4 \mathrm{~d}$ of the $7 \mathrm{~d}$ culture period was significantly higher than in the control slices $(p=0.0002)$, showing no significant difference from the slices exposed to the indoleamine for the whole period. In contrast, cultures exposed to 5-HT during the last $3 \mathrm{~d}$ of the culture period did not show an increase in the proportion of Glu neurons. No significant changes in any cell population were observed after exposure to NA or DA (Fig. $2 B$ ). The proportion of GABAcontaining neurons reached $\sim 40 \%$ in all conditions, a significant increase $(p=0.009)$ over the proportion estimated in cultures prepared from E14 animals. Counts of TUJ1-labeled cells in the 5-HT-treated and control cultures also showed no difference between the two groups, with these cells comprising a little more than $70 \%$ of the overall cell population.

A different picture emerged in cultures prepared from E19 animals (Fig. 2C). In these cultures, when maintained in control conditions, the proportion of Glu neurons $(41.1 \%)$ was markedly higher than in control slices prepared from E14 $(p=0.02)$ or E16 $(p=0.03)$ animals; however, there was no significant difference in the proportions of these neurons between the control and the 5-HT-treated slices. The proportion of GABA-containing neurons in control cultures was reduced to $23.7 \%$ as compared with $41.3 \%$ estimated for E16 slices ( $p=0.0006)$, whereas GFAP-labeled cells increased to $17.3 \%$ compared with $2.7 \%$ observed in E16 cultures $(p=0.0004)$. Other cell types (nestin, CB, CR) were present in proportions similar to those found in slices prepared from E16 animals. 5-HT treatment did not alter these proportions.

To examine whether slices prepared from E16 embryos and cultured for an additional $3 \mathrm{~d}$ could acquire the same neurochemical composition as cultures prepared at E19, we kept a number of these cultures for a total of 10 DIV. When these slices were dissociated and immunostained, it was found that the proportion of Glu-containing neurons was significantly $(p=0.05)$ lower than those observed in E19 cultures and not markedly different from that estimated in E16 slices kept for 7 DIV. This suggested that the proportion of Glu-labeled neurons was related to the age of the animal used to prepare the culture.

The effect of 5-HT on the proportion of Glu neurons appeared to be dose-dependent. Specifically, the proportion of these neurons in the slice cultures was not altered by application of 20-40 $\mu \mathrm{M}$ indoleamine. At greater concentrations, however, Glu neurons increased in number significantly $(p=0.05)$ compared with control cultures, reaching highest levels at concentrations ranging between 120 and $200 \mu \mathrm{M}$. Treatment with excess of $250 \mu \mathrm{M} 5-\mathrm{HT}$ had toxic effects on the slice cultures as assessed by the color of the medium and the appearance of the cells at the dissociation stage. HPLC was used to determine the concentration of 5-HT available to the cultures. In cultures treated with $200 \mu \mathrm{M} 5-\mathrm{HT}$, measurements at $6 \mathrm{hr}$ intervals during the $2 \mathrm{~d}$ period between the start of the culture and the first change of medium showed that 

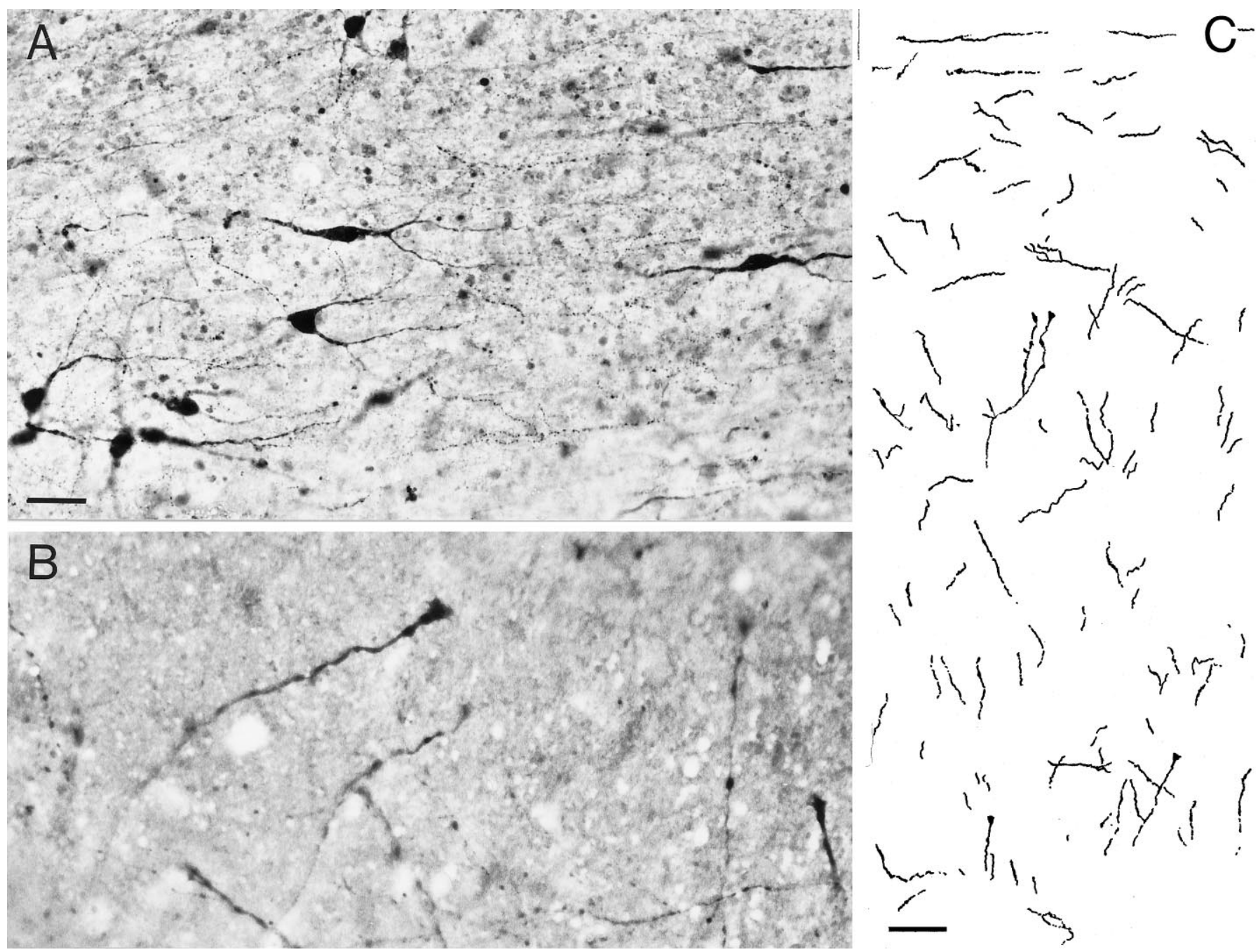

Figure 3. Co-cultures of cortical slices with slices through the midbrain containing the raphe nuclei. $A$, Numerous serotonergic neurons were visualized in the raphe slice. 5-HT-containing fibers innervated the entire cortical slice as shown in a camera lucida drawing $(C)$; pia is at the top. The 5-HT fibers in the cortex were thick and varicose, often having growth cones at their tips $(B)$. Scale bars: $A, 20 \mu \mathrm{m} ; C, 100 \mu \mathrm{m}$.

the concentration was reduced to $153.6 \pm 14.9 \mu \mathrm{M}$ by $18 \mathrm{hr}$ after application and remained virtually unchanged thereafter (measurements ranged between $151 \pm 12.0$ and $169.2 \pm 11.3 \mu \mathrm{M})$. A range of concentrations were tested for the other monoamines up to $100 \mu \mathrm{M}$ for NA and $50 \mu \mathrm{M}$ for DA. Higher concentrations of these monoamines had deleterious effects on the slice cultures.

\section{Co-cultures}

To confirm the observed increase in the proportion of Glupositive cells in cortical slices cultured in the presence of 5-HT, we exposed slices to their natural source of 5-HT, namely the serotonergic cells of the raphe nuclei in the midbrain. Co-cultures of E16 cortical slices and slices taken from E19 raphe nuclei were grown side by side for $7 \mathrm{~d}$. Co-cultures were then fixed and stained with anti-5-HT antibody that revealed a number of large immunoreactive cell somata in the raphe nuclei giving rise to numerous 5-HT-containing processes (Figs. $3 A$ ). These processes were seen to invade the whole cortical slice (Fig. $3 C$ ). In agreement with earlier descriptions of the 5-HT innervation of the cortex (Papadopoulos et al., 1987), they showed predominantly an orientation parallel to the pial surface in layer I and vertical or oblique orientations in the remaining cortical thickness. These seroton- ergic processes were relatively thick and sparsely branched and showed a typical beaded appearance and frequent growth cones at their tips (Fig. 3B). Electron microscopical examination of single ultrathin sections and of 10 serially cut varicosities showed that these processes did not form synaptic contacts with other neuronal elements in the cortical slice.

A number of cortical slices from these co-cultures were dissociated as described above and immunostained, and the mean proportion of Glu-positive cells was assessed. In these slices, Glu neurons made up $32 \%$ of the cell population as compared with $22.8 \%$ in the control group, a difference that was statistically significant ( $p=0.002$ ) (Fig. $4 A)$.

We used HPLC as a further means of determining changes in Glu content in cortical slices brought about by co-culturing with slices containing the raphe nuclei. The mean concentration of Glu in the slices of cortex co-cultured with raphe nuclei was 4.123 $\mu \mathrm{mol} / 1$ as compared with $1.711 \mu \mathrm{mol} / 1$ in the control cultures, showing an increase of $141 \%$ on average $(p=0.028)$ (Fig. $4 B)$.

\section{BrdU labeling}

To reveal possible changes in proliferation brought about by culturing E16 slices in 5-HT-containing medium, we exposed 

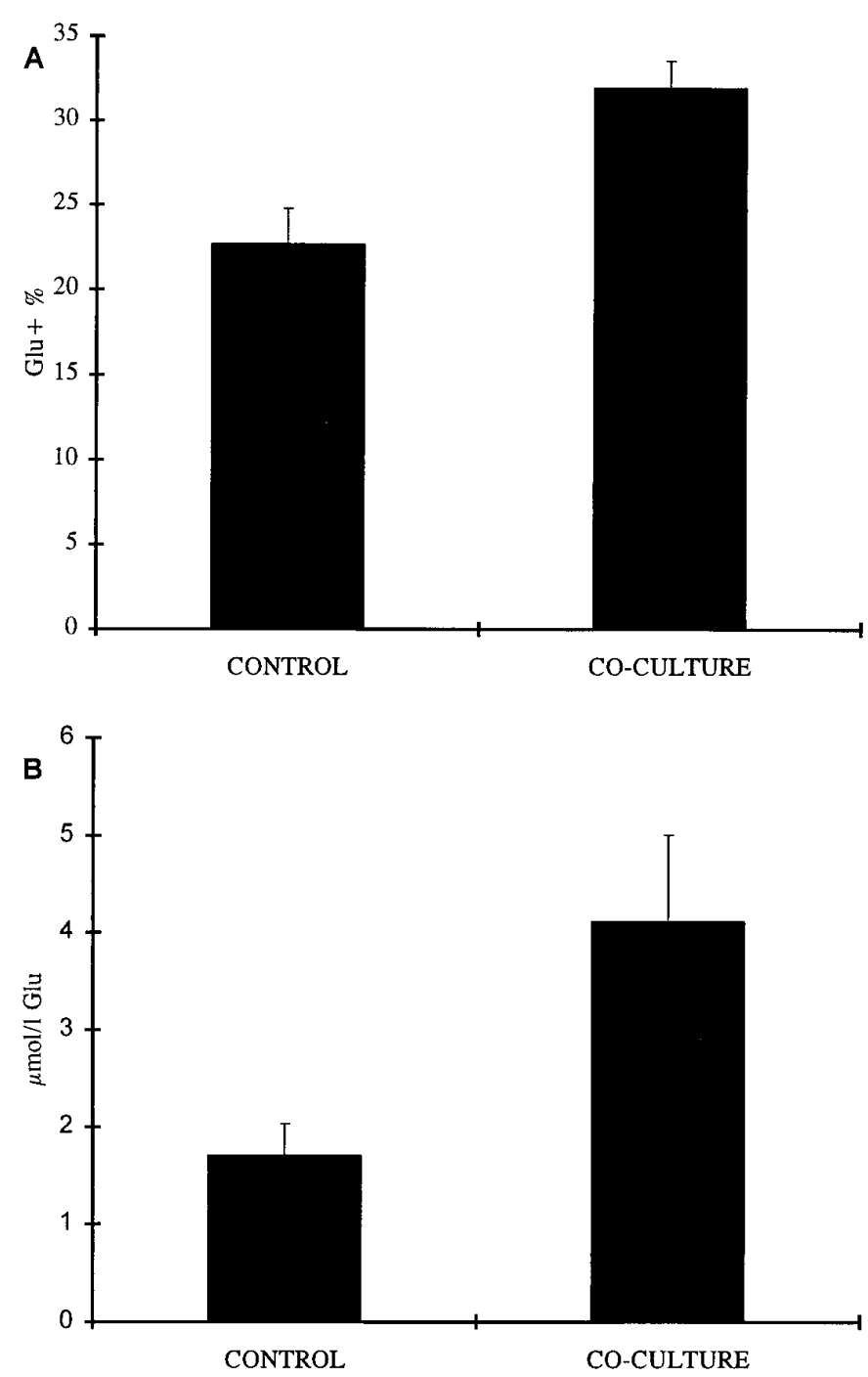

Figure 4. The effects of co-culturing cortical slices with slices containing the raphe nuclei. Both the proportion of Glu-containing neurons in the culture $(A)$ and the Glu content of the culture as measured by HPLC $(B)$ were significantly increased as compared with cortices kept in control conditions.

different cultures to BrdU for $16 \mathrm{hr}$ at each of the 7 DIV and then fixed them. Cells that had incorporated BrdU were immunohistochemically identified (Fig. $5 A$ ). The mean proportion of BrdUlabeled cells in the ventricular zone ranged from $\sim 50 \%$ on the first DIV to $\sim 10 \%$ on the last day in culture, both in control conditions and in the presence of 5-HT. Analysis of these preparations showed no difference in the rate of proliferation between the 5-HT-treated and the control groups (Fig. 5B).

\section{DISCUSSION}

The monoaminergic pathways are among the earliest axonal systems to invade the developing cerebral cortex. Because of their early arrival and widespread distribution throughout the cortex, these axonal systems are in a position to regulate ongoing developmental processes, i.e., cell generation, migration, and differentiation. We used a slice culture preparation to investigate the role(s) of the monoamines 5-HT, NA, and DA in these developmental events during cortical formation. In these preparations, many features of the normal cellular morphology, intrinsic con- nections, and pattern of development remain well preserved (Caeser et al., 1989; Bolz et al., 1990; Roberts et al., 1993); however, the formation of cortical layers is compromised after explantation (Götz and Bolz, 1992), pointing to the importance of extrinsic factors in cortical growth.

\section{Glutamatergic cells}

The main finding to emerge from the present study is that exposure of E16 cortical slices to the indoleamine 5-HT increased the proportion of Glu-containing neurons (and the total Glu content), without affecting the proportions of other neuronal or glial cell types. The catecholamines NA and DA had no effect on the proportions of the different cell populations.

The 5-HT innervation of the cortex originates in the mesencephalic dorsal and median raphe nuclei (Moore et al., 1978). Immunohistochemical studies of the development of the serotonergic system in the rat brain have shown that 5-HT-containing neurons can first be detected in the raphe nuclei at E12. The axons of these neurons begin to elongate shortly thereafter and ascend through the medial forebrain bundle to enter the rostral telencephalon around E16 (Lidov and Molliver, 1982a,b; Wallace and Lauder, 1983; Aitken and Törk, 1988). On arriving in the cortical anlage, 5-HT axons enter as two tangential sheets, one above and one below the cortical plate. They then gradually arborize, sending branches into all cortical layers. Specific 5-HT receptors have also been localized in the developing cortex of the rat (Whitaker-Azmitia et al., 1987; Hellendall et al., 1992; Leslie et al., 1992; Morilak and Ciaranello, 1993), with some subtypes (e.g., 5- $\mathrm{HT}_{3}$ ) (Johnson and Heinemann, 1995) expressed in neuroepithelial cells in the proliferative zones. Serotonergic receptors have been shown to be "functional" in embryonic life (Whitaker-Azmitia et al., 1987), further supporting a role for the serotonergic system in the early stages of cortical development.

The first appearance and subsequent development of the two neuronal cell types, characterized by the presence of either Glu or GABA, have been studied in the developing cortex of the rat in vivo (Van Eden et al., 1989; Dori and Parnavelas, 1996) and in slice cultures (Götz and Bolz, 1994). In the present study, Glucontaining neurons were present in slices prepared from all three embryonic ages (E14, E19, E19) and cultured for $7 \mathrm{~d}$. Their proportion increased from $20 \%$ of all cortical cells in the early cultures to $\sim 40 \%$ in slices taken from E19 rats. This is consistent with the relatively late appearance of Glu in pyramidal neurons (Dori and Parnavelas, 1996). Lineage studies have shown that the expression of the neurotransmitters Glu and GABA in cortical neurons is specified early in corticogenesis (Mione et al., 1994). This determination is likely to depend on the interaction between the inherent properties of the cells and the local environmental signals to which these cells are exposed. The finding that the proportion of Glu-containing neurons did not change in E16 slices cultured for 10 instead of $7 \mathrm{~d}$ and the fact that this proportion was considerably lower than in slices of comparable "age" but prepared from older fetuses (E19/7DIV) suggest that it is the stage of explantation rather than the age of the cells that determines the size of the Glu neuronal population. They also suggest that part of the cell population that would differentiate into glutamatergic neurons in vivo does not do so in this in vitro situation, implying the importance of some extrinsic factor(s) that the cells are deprived of after explantation.

The addition of 5-HT into the medium of E16 cultures resulted in a marked increase in the proportion of Glu neurons. A similar albeit somewhat smaller increase was also observed in cortices 

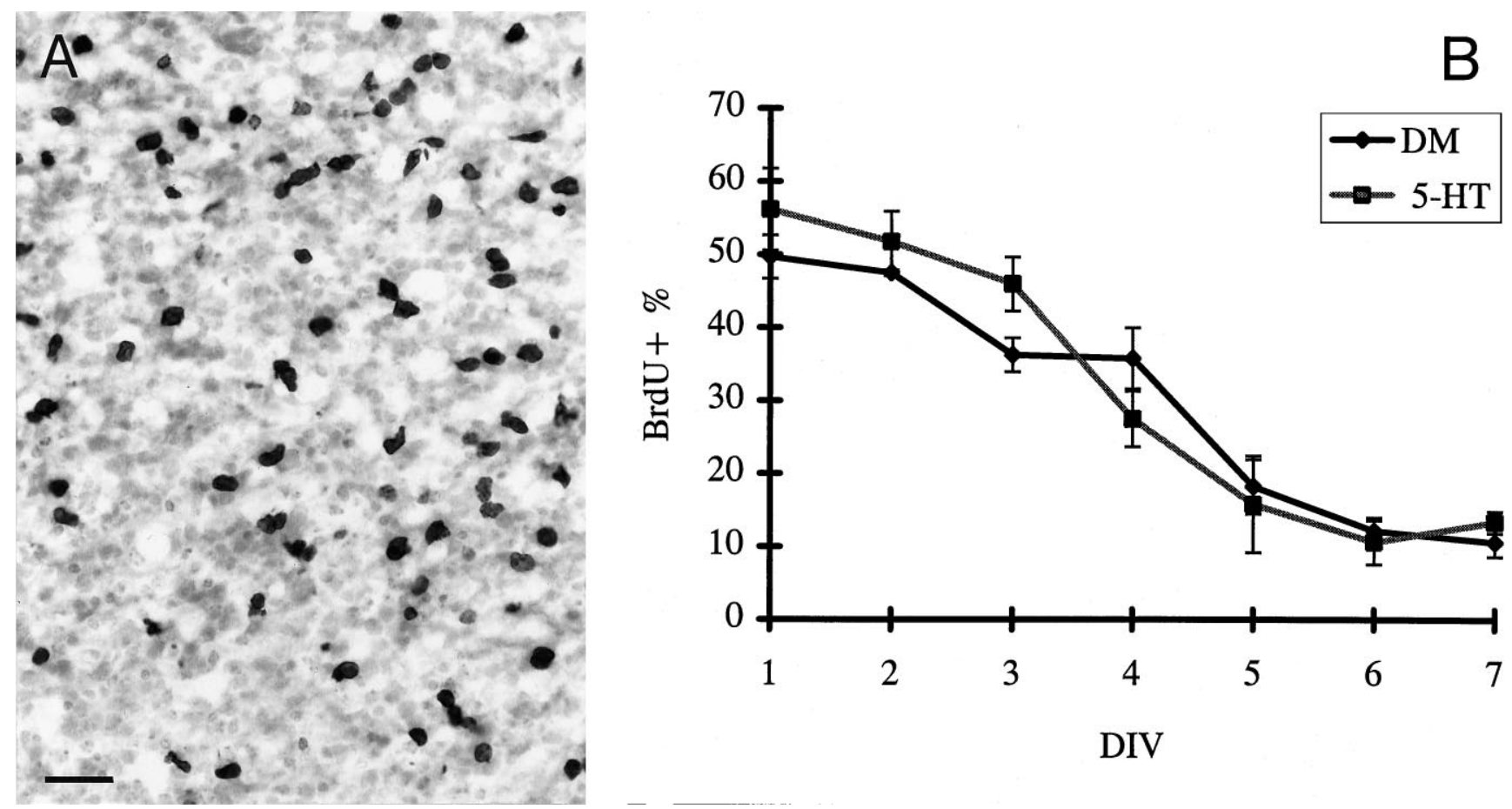

Figure 5. BrdU incorporation in cortical slices. In cryostat sections of cortical slices, BrdU-immunolabeled cell nuclei appeared darkly stained $(A)$. Scale bar, $50 \mu \mathrm{m}$. The incorporation of BrdU did not differ between cultures exposed to 5-HT and cultures kept in control conditions; in both cases, the proportion of immunolabeled cells ranged from $\sim 50 \%$ (on the first day) to $\sim 10 \%$ (on the seventh day); note the very rapid drop in BrdU incorporation after 3 DIV $(B)$.

cultured together with slices containing the raphe nuclei. Serotonergic axons arising in the raphe invaded the cortex as thick and varicose fibers, occasionally giving rise to short branches. Electron microscopical examination of single ultrathin sections and of serial sections of labeled varicosities revealed that these axons did not engage in synaptic contacts with neuronal elements in the cortex, consistent with results of earlier studies of synaptogenesis (Wolff, 1978). This would suggest that 5-HT does not exert its effect through synapses, in agreement with the notion of nonsynaptic release of transmitters acting as regulatory factors early in development. Nonsynaptic release of 5-HT from developing neurons has been documented in vitro (Ugrumov et al., 1989). This release can take place through either varicosities, as proposed by Reisert et al. (1989), or growth cones, a phenomenon observed with a number of neurotransmitters (Hume et al., 1983; Lockerbie et al., 1985), or both.

Why is the effect in the co-culture experiment not as pronounced as that after addition of 5-HT into the culture medium? This may simply be attributable to differences in the concentration of 5-HT in the two experimental paradigms, with cells in the raphe nuclei requiring a certain amount of time after placement into culture to reestablish a normal level of metabolic activity. Regardless of the concentration of 5-HT available to cells in the slice, innervation of the cortex by 5-HT-containing axons resulted in more than double the amount of Glu as measured by HPLC.

Is the increased proportion of Glu neurons attributable to increased proliferation in the cortex after exposure to 5-HT? The selective mitogenic action of 5-HT on progenitors of glutamatergic cells is not supported by the experiments of BrdU incorporation, because levels of incorporation did not differ between the control and 5-HT-treated groups. If cell proliferation is not af- fected by 5 -HT and the proportions of other neuronal and glial cell types were not altered, what is the source of the increased Glu-containing neuronal population? There are two possibilities that may account for this increase: (1) selective survival of glutamatergic neurons and (2) differentiation of newly generated neurons. The first possibility can be ruled out, because cell counts did not reveal differences in the proportions of all other cell types between the control and 5-HT-treated groups. This would then argue in favor of either an earlier onset of Glu expression or increased Glu content in developing cortical neurons or both. This is supported further by the fact that the proportion of unstained (non-Glu, -GABA, -CB, -CR, -nestin, -GFAP) cells is diminished in the 5-HT-treated cultures.

The hypothesis that 5-HT influences the onset of differentiation of prospective target neurons during embryogenesis was first put forth by Lauder and Krebs (1978) in a study in the superior colliculus and hippocampus of rats that had received the 5-HTdepleting drug $p$-chlorophenylalanine. These authors suggested that increased differentiation could occur as a direct interaction between 5-HT axons and proliferating progenitor cells or because of circulating monoamines influencing dividing cells. Our results, however, suggest that 5-HT does not act on dividing cells, but rather acts on newly generated postmitotic neurons. The addition of 5-HT in the culture medium seemed to compensate for the isolation of cortical cells from the required signal(s), in that it increased the proportion of Glu-containing neurons to a level equal to that observed near the end of the period of neurogenesis. This suggests that 5-HT may be one of the signals that immature cells in the cortex require to follow the correct differentiation pathway, without implying that this neurotransmitter is involved in the choice of the pathway. 


\section{GABAergic and other cell types}

The early presence of GABA and GABA-containing neurons in the cortex has been demonstrated in a number of neurochemical (Coyle and Enna, 1976) and immunocytochemical (Wolff et al., 1984; Van Eden et al., 1989; Cobas et al., 1991) studies. In our slice preparations, GABAergic neurons outnumber Glu-containing neurons, comprising about one third of all cells in the cultures prepared from E14 animals. Their proportion is increased at E16 but declines to $\sim 20 \%$ of the total cell population at E19. Local environmental factors that may be involved in the regulation of GABA expression in the cortex are not known. The present study has demonstrated that the differentiation of the GABAergic phenotype is not influenced by the monoaminergic systems, and it precludes the possibility that the increased number of Glu-containing neurons after 5-HT application is a consequence of a choice that neurons have between expressing Glu or GABA.

The proportions of cells containing the calcium-binding proteins $\mathrm{CB}$ and $\mathrm{CR}$ were also not affected by the presence of monoamines. These proteins, implicated in functions related to intracellular calcium buffering (Blaustein, 1988; Baimbridge et al., 1992), are thought to define subpopulations of cortical nonpyramidal neurons (Demeulemeester et al., 1989). Lineage studies in the cerebral cortex (Mione et al., 1994) have shown that the expression of these proteins is not lineage dependent and is likely to be determined by environmental factors. Evidence of a close relationship between 5-HT fibers and cortical nonpyramidal neurons containing calcium-binding proteins (Hornung and Celio, 1992) has prompted the suggestion that the expression of these proteins is influenced by serotonergic afferents; however, the observed close association is unlikely to be established during neurogenesis, and our findings do not support such an influence during that period. In summary, the present study indicates that 5-HT promotes the differentiation of a specific type of neuron in the early stages of cortical formation.

\section{REFERENCES}

Aitken AR, Törk I (1988) Early development of serotonin-containing neurons and pathways as seen in wholemount preparations of the fetal rat brain. J Comp Neurol 274:32-47.

Altman J, Bayer SA (1995) Atlas of the prenatal rat brain development. Boca Raton, FL: CRC.

Baimbridge KG, Celio MR, Rogers JH (1992) Calcium-binding proteins in the nervous system. Trends Neurosci 15:303-308.

Bennett-Clarke CA, Leslie MJ, Lane RD, Rhoades RW (1994) Effect of serotonin depletion on vibrissa-related patterns of thalamic afferents in the rat's somatosensory cortex. J Neurosci 14:7594-7607.

Berger B, Verney C (1984) Development of the catecholamine innervation in rat neocortex: morphological features. In: Monoamine innervation of cerebral cortex (Descarries L, Reader TR, Jasper HH, eds), pp 95-121. New York: Alan R. Liss.

Blaustein MP (1988) Calcium transport and buffering in neurons. Trends Neurosci 11:438-443.

Bolz J, Novak N, Götz M, Bonhoeffer T (1990) Formation of targetspecific neuronal projections in organotypic slice cultures from rat visual cortex. Nature 346:359-362.

Caeser M, Bonhoeffer T, Bolz J (1989) Cellular organization and development of slice cultures from rat visual cortex. Exp Brain Res $77: 234-244$

Chubakov AR, Gromova EA, Konovalov GV, Sarkisova EF, Chumasov EI (1986) The effects of serotonin on the morpho-functional development of rat cerebral neocortex in tissue culture. Brain Res 369:285-297.

Cobas A, Fairén A, Alvarez Bolado G, Sánchez MP (1991) Prenatal development of the intrinsic neurons of the rat neocortex: a comparative study of the distribution of GABA-immunoreactive cells and the GABA $_{\mathrm{A}}$ receptor. Neuroscience 40:375-397.

Coyle JT, Enna SJ (1976) Neurochemical aspects of the ontogenesis of GABAnergic neurons in the rat brain. Brain Res 111:119-133.
Demeulemeester H, Vandesande F, Orban GA, Heizmann CW, Pochet R (1989) Calbindin D-28K and parvalbumin immunoreactivity is confined to two separate neuronal subpopulations in the cat visual cortex, whereas partial coexistence is shown in the dorsal lateral geniculate nucleus. Neurosci Lett 99:6-11.

Donzati BA, Yamamoto BK (1988) An improved and rapid HPLC-EC method for the isocratic separation of amino acid neurotransmitters from brain tissue and microdialysis perfusates. Life Sci 43:913-922.

Dori I, Parnavelas JG (1996) The development of excitatory transmitter amino acid-containing neurons in the rat visual cortex. A light and electron microscopic immunocytochemical study. Brain Res 110:347-359.

Dori I, Dinopoulos A, Cavanagh ME, Parnavelas JG (1992) Proportion of glutamate- and aspartate-immunoreactive neurons in the efferent pathways of the rat visual cortex varies according to the target. J Comp Neurol 319:191-204.

Fagg GE, Foster AC (1983) Amino acid neurotransmitters and their pathways in the mammalian central nervous system. Neuroscience 9:701-719.

Ferri RT, Levitt P (1995) Regulation of regional differences in the differentiation of cerebral cortical neurons by EGF family-matrix interactions. Development 121:1151-1160.

Gilbert CD (1983) Microcircuitry of the visual cortex. Annu Rev Neurosci 6:217-247.

Götz M, Bolz J (1992) Formation and preservation of cortical layers in slice cultures. J Neurobiol 23:783-802.

Götz M, Bolz J (1994) Differentiation of transmitter phenotypes in rat cerebral cortex. Eur J Neurosci 6:18-32.

Hellendall RP, Schambra U, Liu J, Breese GR, Millhorn DE, Lauder JM (1992) Detection of serotonin receptor transcripts in the developing nervous system. J Chem Neuroanat 5:299-310.

Hornung JP, Celio MR (1992) The selective innervation by serotoninergic axons of calbindin-containing interneurons in the neocortex and hippocampus of the marmoset. J Comp Neurol 320:457-467.

Hume RI, Role LW, Fischbach GD (1983) Acetylcholine release from growth cones detected with patches of acetylcholine receptor-rich membranes. Nature 305:632-634.

Johnson DS, Heinemann SF (1995) Embryonic expression of the 5- $\mathrm{HT}_{3}$ receptor subunit, $5-\mathrm{HT}_{3} \mathrm{R}-\mathrm{A}$, in the rat: an in situ hybridization study. Mol Cell Neurosci 6:122-138.

Kalsbeek A, Voorn P, Buijs RM, Pool CW, Uylings HBM (1988) Development of the dopaminergic innervation in the prefrontal cortex of the rat. J Comp Neurol 269:58-72.

Kasamatsu T, Pettigrew JD (1976) Depletion of brain catecholamines: failure of ocular dominance shift after monocular occlusion in kittens. Science 194:206-209.

Lauder JM (1990) Ontogeny of the serotonergic system in the rat: serotonin as a developmental signal. Ann NY Acad Sci 600:297-313.

Lauder JM (1993) Neurotransmitters as growth regulatory signals: role of receptors and second messengers. Trends Neurosci 16:233-240.

Lauder JM, Krebs H (1978) Serotonin as a differentiation signal in early neurogenesis. Dev Neurosci 1:15-30.

Lee MK, Tuttle JB, Rebhun LI, Cleveland DW, Frankfurter A (1990) The expression and posttranslational modification of neuron-specific beta-tubulin isotype during chick embryogenesis. Cell Motil Cytoskeleton 17:118-132.

Lendahl U, Zimmerman LB, McKay RD (1990) CNS stem cells express a new class of intermediate filament protein. Cell 60:585-595.

Leslie MJ, Bennett Clarke CA, Rhoades RW (1992) Serotonin 1B receptors form a transient vibrissa-related pattern in the primary somatosensory cortex of the developing rat. Dev Brain Res 69:143-148.

Levitt P, Moore RY (1979) Development of the noradrenergic innervation of neocortex. Brain Res 162:243-259.

Levitt P, Harvey JA, Friedman E, Simansky K, Murphy EH (1997) New evidence for neurotransmitter influences on brain development. Trends Neurosci 20:269-274.

Lidov HG, Molliver ME (1982a) An immunohistochemical study of serotonin neuron development in the rat: ascending pathways and terminal fields. Brain Res Bull 8:389-430.

Lidov HG, Molliver ME (1982b) Immunohistochemical study of the development of serotonergic neurons in the rat CNS. Brain Res Bull 9:559-604.

Lockerbie RO, Gordon-Weeks PR, Pearce BR (1985) Growth cones 
isolated from developing rat forebrain: uptake and release of GABA and noradrenaline. Dev Brain Res 21:265-275.

LoTurco JL, Owens DF, Heath MJS, Davis MBE, Kriegstein AR (1995) GABA and glutamate depolarize cortical progenitor cells and inhibit DNA synthesis. Neuron 15:1287-1298.

McConnell SK (1991) The generation of neuronal diversity in the central nervous system. Annu Rev Neurosci 14:269-300.

McCormick DA, Connors BW, Lighthall JW, Prince DA (1985) Comparative electrophysiology of pyramidal and sparsely spiny stellate neurons of the neocortex. J Neurophysiol 54:782-806.

Mione MC, Danevic C, Boardman P, Harris B, Parnavelas JG (1994) Lineage analysis reveals neurotransmitter (GABA or glutamate) but not calcium-binding protein homogeneity in clonally related cortical neurons. J Neurosci 14:107-123.

Moore RY, Halaris AE, Jones BE (1978) Serotonin neurons of the midbrain raphe: ascending projections. J Comp Neurol 180:417-438.

Morilak DA, Ciaranello RD (1993) Ontogeny of 5- $\mathrm{HT}_{2}$ receptor immunoreactivity in the developing rat brain. Neuroscience 55:869-880.

Papadopoulos GC, Parnavelas JG, Buijs RM (1987) Light and electron microscopic immunocytochemical analysis of the serotonin innervation of the rat cerebral cortex. J Neurocytol 16:883-892.

Parnavelas JG, Luder R, Pollard SG, Sullivan K, Lieberman AR (1983) A qualitative and quantitative ultrastructural study of glial cells in the developing visual cortex of the rat. Philos Trans R Soc Lond [Biol] 301:55-84.

Parnavelas JG, Papadopoulos GC, Cavanagh ME (1988) Changes in neurotransmitters during development. In: Cerebral cortex, Vol 7, Development and maturation of cerebral cortex (Peters A, Jones EG, eds), pp 177-209. New York: Plenum.

Parnavelas JG, Dinopoulos A, Davies SW (1989) The central visual pathways. In: Handbook of chemical neuroanatomy, Vol 7, Integrated systems of the CNS, Part II (Björklund A, Hökfelt T, Swanson LW, eds), pp 1-164. Amsterdam: Elsevier.

Reinhard JF, Moskowitz MA, Sved RF, Fernstrom JD (1980) A simple sensitive and reliable assay for serotonin and 5HIAA in brain tissue using liquid chromatography with electrochemical detection. Life Sci 27:905-911.

Reisert I, Han V, Hartwig S, Ahnert-Hilger G, Pilgrim Ch (1989) Rapid maturation of synaptic functions of prenatal serotonergic neurons in short-term cultures: absence of sex differences and hormone effects. Neuroscience 32:133-139.

Roberts JS, O'Rourke NA, McConnell SK (1993) Cell migration in cultured cerebral cortical slices. Dev Biol 155:396-408.

Rockel AJ, Hiorns RW, Powell TPS (1980) The basic uniformity in structure of the neocortex. Brain 103:221-244.

Sillito AM (1984) Functional considerations of the operation of GABAergic inhibitory processes in the visual cortex. In: Cerebral cortex, Vol 2, Functional properties of cortical cells (Jones EG, Peters A, eds), pp 91-117. New York: Plenum.

Szentágothai J (1973) Synaptology of the visual cortex. In: Handbook of sensory physiology, Vol. VII/3, Central processing of visual information, Part B (Jung R, ed), pp 269-324. Berlin: Springer.

Temple S, Qian X (1995) bFGF, neurotrophins, and the control of cortical neurogenesis. Neuron 15:249-252.

Ugrumov MV, Proshlyakova EV, Sapronova A (1989) Development of the hypothalamic 5-hydroxytryptamine system during ontogenesis in rats: uptake and release of 5-hydroxytryptamine in vitro. Neuroscience 32:127-131.

Vaccarino FM, Schwartz ML, Hartigan D, Leckman JF (1995) Basic fibroblast growth factor increases the number of excitatory neurons containing glutamate in the cerebral cortex. Cereb Cortex 5:64-78.

Van Eden CG, Mrzljak L, Voorn P, Uylings HBM (1989) Prenatal development of GABA-ergic neurons in the neocortex of the rat. J Comp Neurol 289:213-227.

Wallace JA, Lauder JM (1983) Development of the serotonergic system in the rat embryo: an immunocytochemical study. Brain Res Bull 10:459-479.

Whitaker-Azmitia PM, Lauder JM, Shemmer A, Azmitia EC (1987) Postnatal changes in serotonin ${ }_{1}$ receptors following prenatal alterations in serotonin levels: further evidence for functional fetal serotonin ${ }_{1}$ receptors. Dev Brain Res 33:285-289.

Wolff JR (1978) Ontogenetic aspects of cortical architecture: lamination. In: Architectonics of the cerebral cortex (Brazier MAB, Petsche H, eds), pp 159-173. New York: Raven.

Wolff JR, Balcar VJ, Zetzsche T, Bottcher H, Schmechel DE, Chronwall BM (1984) Development of GABA-ergic system in rat visual cortex. Adv Exp Med Biol 181:215-239. 